\title{
COMMENTARIES
}

\section{Understanding and Meeting the Needs of the Older Population: A Global Challenge}

Howard Bergman, $\mathrm{MD}^{1}$, Sathya Karunananthan, $\mathrm{MSc}^{2}$, Luis M. G. Robledo, $\mathrm{MD}$, $\mathrm{PhD}^{3}$, Jenny Brodsky, $\mathrm{PhD}^{4}$, Piu Chan, MD, $\mathrm{PhD}^{5}$, Maria Cheung, $\mathrm{BSC}^{6}$, Pascal Bovet, MD, $\mathrm{MPH}^{7}$

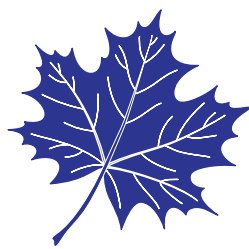

${ }^{1}$ Department of Family Medicine, McGill University, Montreal, QC, Canada; ${ }^{2}$ Department of Epidemiology,

Biostatistics and Occupational Health, McGill University, Montreal, QC, Canada; ${ }^{3}$ Institute of Geriatrics, National

Institutes of Health, Mexico City, Mexico; ${ }^{4}$ Myers-JDC-Brookdale Institute, Jerusalem, Israel; ${ }^{5}$ Capital Medical University, Bejing, China; ${ }^{6}$ University of Waterloo, Waterloo, ON, Canada; ${ }^{7}$ Institut universitaire de médecine sociale et preventive, University of Lausanne, Lausanne, Switzerland

DOI:http://dx.doi.org/10.5770/cgj.16.60

\begin{abstract}
Background

In the past century, there has been a significant rise in life expectancy in almost all regions of the world, contributing to an increasingly older population. The aging of the population, in conjunction with urbanization and industrialization, has resulted in an important epidemiological transition marked by a widespread increase in the prevalence of chronic diseases and their sequelae. Current trends suggest that the transition will have a greater impact on developing countries compared to developed countries. An adequate response to the transition requires a strong emphasis on primary prevention and adequate resource allocation.
\end{abstract}

Key words: aged, health service needs and demands, world health, chronic disease

\section{INTRODUCTION}

Societies around the world are faced with the challenge of improving the health of their populations, meeting their health and social service needs, assuring quality of care, and guaranteeing equity - all the while striving to be costeffective. ${ }^{(1)}$ This challenge is occurring within the context of significant demographic and epidemiological transitions. Albeit in different ways, these transitions and the resulting challenges are being faced both by developed and developing countries. They will have a significant impact on our societies, in terms of the health and well-being of its populations, as well as their economic growth. ${ }^{(2,3)}$ The objective of this article is to present the impact of the aging population on health-care systems in both developed and developing countries, and to discuss potential strategies to address the resulting challenges.

\section{DISCUSSION}

\section{Demographic Transition}

In the past century, there have been significant increases in life expectancy in almost all regions of the world, resulting in an increasingly older population. ${ }^{(4)}$ In many developing countries, the increase in both the relative and absolute number of older persons has been much more rapid than in the developed world. In Mexico, for example, the proportion of over 65 -year-olds is expected to increase from $5 \%$ to $25 \%$ within 50 years (2000 to 2050), whereas in France a similar rise will have occurred over 300 years (1750 to 2050). ${ }^{(5)}$

As well, there have been significant accompanying increases in the "oldest old," that is the population above the age of 80 years. Between 1950 and 2050, the number of people in the world aged over 80 years is expected to increase from 14.5 million to 394.7 million $^{(4)}$ (Figure 1). Because the population over the age of 80 years is growing significantly faster in developing countries, by the year 2050 ,

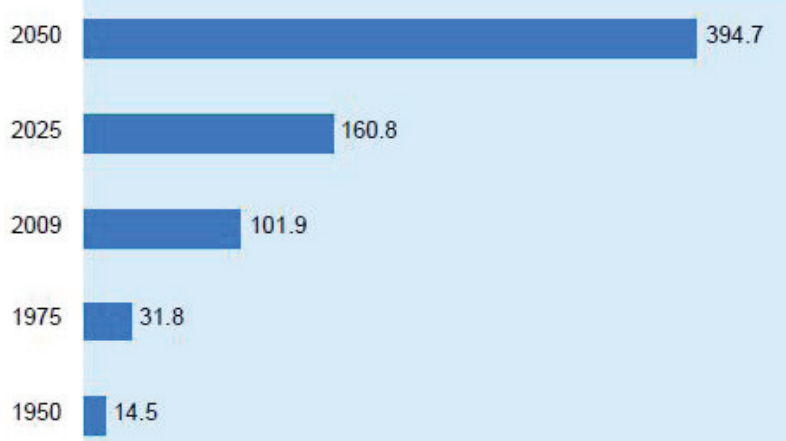

Data from United Nations. ${ }^{(4)}$

FIGURE 1. Actual and projected population aged 80 or over in the world from 1950-2050 
over $70 \%$ of the world's oldest old population will be living in developing countries. ${ }^{(6)}$

Several factors have been associated with the demographic transition. In both developed and developing countries, improved living conditions, education, and accessibility to health care have contributed to prolonging the lifespan of the population..$^{(7)}$ Declining birth rate has contributed to the proportional increase of older persons in the population. In the case of developing countries, related improvements in the specific areas of sanitation, nutrition, and infectious disease control that build on recent technology and socioeconomic development are also frequently cited factors linked to the rapid aging of the population. ${ }^{(8)}$

\section{Epidemiologic Transitions}

An epidemiological transition is an evolutionary framework that links demographic and social changes to modifications in disease patterns within a population. ${ }^{(9)}$ Urbanization and industrialization, in conjunction with the aging of the population, have resulted in an important epidemiological transition, marked by a widespread increase in the prevalence of chronic diseases and their sequelae. Industrialization has contributed to the transition by bringing about important lifestyle changes such as increased tobacco consumption, unhealthy diets, and decreased physical activity, ${ }^{(10,11)}$ which are important risk factors for chronic disease. The aging of the population has amplified the transition further, since an increased lifespan translates into prolonged exposure to chronic disease risk factors. ${ }^{(2)}$

This epidemiological transition is rapid and widespread. $(2,3)$ It is estimated that in the year 2030, chronic noncommunicable diseases will be responsible for more than half of the disease burden in lower-middle and low-income countries $^{(12)}$ (Figure 2). However, the rate of transition and disease patterns across countries are influenced by several country-specific historical, socioeconomic, and biological factors such as war, famine, education, economic growth, and genetic susceptibility to particular diseases. ${ }^{(13)}$ Furthermore, while in developed countries there has been a clear shift from early transition diseases (i.e., infections and malnutrition) to late transition diseases (e.g., cardiovascular disease, diabetes), many developing countries face a "double burden of disease", where both conditions coexist in the population.

\section{The Impact of Two Seemingly Contradictory Trends}

In 1977, Gruenberg wrote about the "failures of success" in reference to the prolonged period of morbidity and disability that has accompanied extended life expectancy. He argued that in an effort to eradicate causes of death rather than causes of disease, medical progress has produced an increase in the prevalence of disabling chronic conditions. ${ }^{(14)}$

Data from developed countries, however, indicate that the postponement of disability has been greater than the increase in life expectancy, thus compressing lifetime disability into a shorter average period, and delaying its onset to an older age. (15) Environmental, social, and biological factors attributed to disability would suggest that the situation in the developed countries is not comparable to that of developing countries. In developed countries, improved medical care, and pharmaceutical and technological advancements are believed to have contributed towards curbing the debilitating effects of chronic diseases. Health-care services are much more limited and risk factors such as tobacco consumption, poor dietary habits, and sedentary lifestyles are on the rise in developing countries. ${ }^{(7)}$ Socioeconomic advancements such as increased education, higher incomes, and improved work conditions observed in developed countries also are not occurring at the same rate in developing countries.

Hence, we are witnessing a sharp increase in chronic disease among older persons in developing countries. This, in turn, may result in an aging population with a significant burden of disability and dependency, leading to increased demands on the individual, the family, and the community, and increased utilization of health-care resources, as well as an increased economic and resource burden to society.

\section{Daunting Challenges}

These demographic and epidemiological transitions represent a daunting challenge for both developed and developing countries. Health-care systems are focused on the treatment of acute illness, and are poorly adapted to chronic disease and disability. The needs of older persons with multiple chronic diseases are not met, leading to increased risk of deteriorating health, as well as increased health-care use and costs. Developed countries are struggling to control the costs of health care while providing for the increasing demands. The traditional model based on institutional care is neither appropriate nor sustainable given the evolving and growing needs of the population.

Although the onset of the epidemiological transition is relatively recent to developing countries, it is occurring at a higher pace, with levels of income that are much lower, compared to developed countries. ${ }^{(16)}$ In addition, developing countries are faced with the double burden of poorly controlled infectious diseases alongside the increasing demands for management of chronic conditions. Due to limited resources, these countries often allocate low priority to chronic diseases, thereby delaying potentially cost-effective interventions.

\section{Achieving Improved Health and Functional Status in Older Persons}

Meeting the challenge of the aging population and responding to the needs of older persons requires a better understanding of aging, frailty, disability, and appropriate interventions. The objectives need to be two-fold: first, a strong emphasis on prevention of chronic disease and promotion of healthy 
Low- and middle-income countries

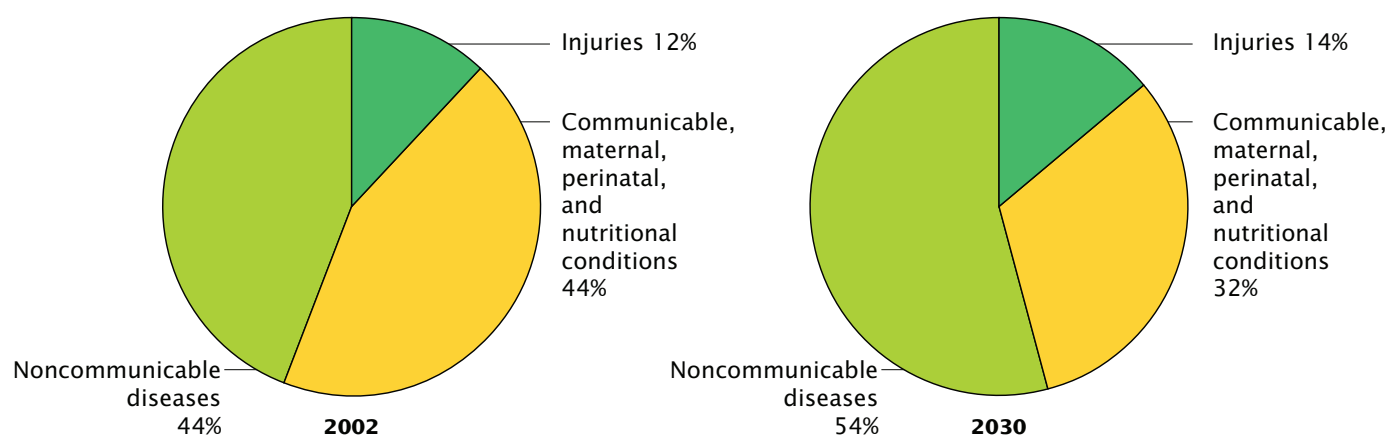

High-income countries
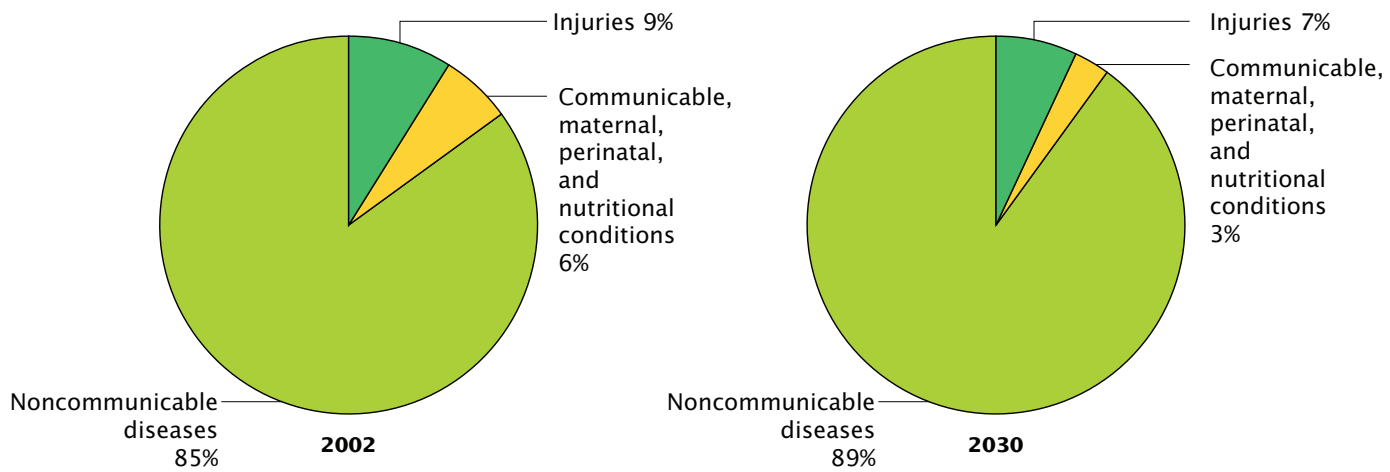

Data from the Global Aging Census Bureau. ${ }^{(12)}$

FIGURE 2. Deaths due to non-communicable disease in high-income, lower- and middle-income countries; comparison between data in 2002 and projected 2030

aging in order to delay the onset of disability and dependency; second, appropriate services for older persons when they do develop disabilities.

Both of these objectives will result in decreased burden on individuals, families, and society. Projections suggest that delaying the onset of disability and dependence by only one or two years may reduce the population's needs for long-term care and institutional resources significantly. ${ }^{(17)}$ At the same time, health and social care to provide for the complex needs of older persons with disabilities can improve the well-being of these individuals and their families in a cost-effective manner. ${ }^{(18,19)}$ The challenge then becomes how to translate these objectives and interventions into a coherent system of health and social service in the context of limited resources.

These objectives call for a multilevel and multidimensional strategy, including a life-course approach to chronic diseases, which suggests that functional status and agerelated chronic diseases are a result of exposure to risk factors throughout one's lifetime, possibly beginning even before birth. ${ }^{(12)}$ By applying the life-course approach as a framework for the promotion of healthy aging and the prevention of disability and frailty, interventions targeted early in life may have multiple long-term benefits towards healthy aging.

However, the life-course approach does not preclude the possibility of targeting interventions for older persons who are already suffering from chronic diseases and/or disability. There is evidence of effective primary prevention programs for older persons. ${ }^{(20)}$ Furthermore, the relationship between health, frailty, and disability is a dynamic one, such that latelife interventions for those who are already affected by chronic disease are also worth exploring further. ${ }^{(21)}$

When the chronic disease epidemic first became apparent in developed countries, etiologic knowledge was very limited. Consequently, the approach to managing chronic diseases was largely based on the screening and treatment of high-risk individuals and the clinical management of symptoms. As the prevalence of these diseases increased, these types of interventions proved to be extremely costly. Now that risk factors for most chronic conditions are well-established, there are opportunities for primary prevention through population-wide preventive activities. These include integrating and orienting prevention into health delivery, professional training, and 
practice. ${ }^{(22)}$ Primary prevention is appealing because it has the potential to decrease the incidence of disease, while requiring far fewer resources. ${ }^{(20)}$ For developing countries that are still in the early stages of the upswing in chronic disease, primary prevention offers a key opportunity to curb the epidemic. ${ }^{(2)}$

In addition to community-based preventive interventions, there is an urgent need for health-care services adapted to older persons with chronic disease and disability. Developed countries are now trying to reverse the institutional "bricks and mortar" approach to serving the aging population. They are instead evolving towards a system based on primary medical and community care. For developing countries, this may be a crucial time to develop and orient similarly, so as to avoid the heavy resource burden of the institutional approach. Indeed, a 2010 Global Aging report forecasted that an increase in long-term care costs between 2010 and 2050 in developed countries is considered a higher economic risk than the informal family-based care networks more commonly practiced in developing countries. ${ }^{(23)}$ Thus, strong family and community involvement, as well as utilization of traditional healing resources, can be combined with the training of the professional workforce in order to more adequately serve the aging population.

In addition, social and economic factors must be considered in the development of new support systems in developing countries. As shown by the "Seguro Popular" in Mexico, securing a minimum wage for survival and simultaneously providing easier access to health care can have important effects on health-care utilization and costs. ${ }^{(24)}$

\section{CONCLUSION}

There is clear evidence of an epidemiological transition resulting in a sharp increase in the incidence of non-communicable chronic diseases worldwide. Historical, socioeconomic, biological, and political factors will all play an important role in determining the impact of this transition. While current trends suggest that the transition may lead to greater disability in older persons in developing countries, several potential interventions, including primary prevention, may curb these trends. Transferring funds and resources into primary and community-based care, supporting family caregiving, and enhancing access to health care can also contribute to meeting the challenges of an aging population.

There are no simple solutions, but there are directions on emerging choices for both developed and developing countries. Exchanging lessons on effective programs and interventions can support the development of informed policies and evidence-based programs. Data on the health and functional status of the populations, policies, and intervention need to be shared, discussed, and debated. International collaboration for the development of population studies on aging also contributes towards a better understanding of present and future needs. Ultimately, public health policies and endeavors need to be based on well-founded evidence about the health and functional status of the older population. Additionally, they need to be tailored to the health and social systems of their respective countries. Existing infrastructures can thereby be used more effectively to promote the health and functional well-being of older populations.

\section{ACKNOWLEDGEMENTS}

Preparation of this manuscript was supported by the Dr. Joseph Kaufmann Chair in Geriatric Medicine.

\section{CONFLICT OF INTEREST DISCLOSURES}

The authors declare that no conflicts of interest exist.

\section{REFERENCES}

1. World Health Organization. The World Health Report 2000: Health systems: improving performance. Geneva: World Health Organization Press; 2000.

2. Bovet $P$. The cardiovascular disease epidemic: global, regional, local [editorial]. Trop Med Int Health. 2002;7(9):717-21.

3. World Health Organization. Preventing chronic disease: a vital investment. Geneva: World Health Organization Press; 2005.

4. Department of Economic and Social Affairs (DESA). World population aging 2009. New York: DESA, United Nations; 2009.

5. Chande RH. El envejecimiento en Mexico: El siguiente reto de la transicion demografica. Tijuana,Mexico: Colegio de la Frontera Norte; 2003.

6. Department of Economic and Social Affairs (DESA). World population aging: 1950-2050. New York: DESA Population Division, United Nations; 2001.

7. Dominguez LJ, Galioto A, Ferlisi A, et al. Ageing, lifestyle modifications and cardiovascular disease in developing coutries. J Nutri Health Aging. 2006;10(2):143-49.

8. Bovet P, Ross AG, Gervasoni JP, et al. Distribution of blood pressure, body mass index and smoking habits in the urban population of Dar es Salaam, Tanzania, and associations with socioeconomic status. Int J Epidemiol. 2002;31(1):240-47.

9. Omran AR. The epidemiologic transition. A theory of the epidemiology of population change. Milbank Mem Fund $Q$. 1971;49(4):509-38.

10. Lee IM, Shiroma EJ, Lobelo F, et al. Effect of physical inactivity on major non-communicable diseases worldwide: an analysis of burden of disease and life expectancy. Lancet. 2012;380(9638):219-29.

11. Kohl HW 3rd, Craig CL, Lambert EV, et al. The pandemic of physical inactivity: global action for public health. Lancet. 2012;380(9638):294-305.

12. Kinsella K, He W. An aging world: 2008. International Population Reports. Washington (DC): US Government Printing Office; June 2009:51-72.

13. Gutiérrez-Robledo LM. Looking at the future of geriatric care in developing countries. J Gerontol A Biol Sci Med Sci. 2002;57(3):162-67. 
14. Gruenberg EM. The failures of success. Milbank $Q$. 2005;83(4):779-800.

15. Jacobzone S. Coping with aging: international challenges. Health Aff (Millwood). 2000;19(3):213-25.

16. Brodsky J, Habib J, Hirschfeld M, et al. Care of the frail elderly in developed and developing countries: the experience and the challenges. Aging Clin Exp Res. 2002;14(4):279-86.

17. Monnier A. Le baby-boom: suite et fin. Population et societies. 2007;431:1-4.

18. Bergman H, Beland F, Perrault A. The global challenge of understanding and meeting the needs of the frail older population. Aging Clin Exp Res. 2002;14(4):223-25.

19. Beland F, Bergman H, Lebel P, et al. A system of integrated care for older persons with disabilities in Canada: results from a randomized controlled trial. J Gerontol A Biol Sci Med Sci. 2006;61(4):367-73.

20. Christensen K, Doblhammer G, Rau R, et al. Ageing populations: the challenges ahead. Lancet. 2009;374(9696):1196-208.
21. Bergman H, Beland F, Karunananthan S, et al. Développement d'un cadre de travail pour comprendre et étudier la fragilité. Gérontologie et société. 2004;109(2):16-29.

22. Daar AS, Singer PA, Persad DL, et al. Grand challenges in chronic non-communicable diseases. Nature. 2007; 450(7169):494-96.

23. Mrsnik M. Global aging 2010: an irreversible truth. New York: Standard and Poor's Financial Services LLC; 2010.

24. King G, Gakidou E, Imai K, et al. Public policy for the poor? A randomised assessment of the Mexican universal health insurance programme. Lancet. 2009;373(9673):1447-54.

Correspondence to: Howard Bergman, MD, Department of Family Medicine, McGill University, 515-517 Pine Ave West, Montreal, QC H2W 1S4, Canada

E-mail:howard.bergman@mcgill.ca 